\title{
Drought assessment and rainfall trend analysis in a southern Mediterranean watershed during the last century (1914-2011)
}

\author{
A. Ababou ${ }^{1}$, AEK. Bouthiba ${ }^{2}$, M. Chouieb ${ }^{3}$ and H.A. Reguieg Yssaad ${ }^{3}$ \\ ${ }^{1}$ Faculty of Nature and Life Sciences, Laboratory of Natural Bio-Resources, University Hassiba Ben Bouali, Chlef, Algeria \\ ${ }^{2}$ Faculty of Nature and Life Sciences, University Hassiba Ben Bouali, Chlef, Algeria \\ ${ }^{3}$ Faculty of Nature and Life Sciences, University Abd El Hamid Ibn Badis, Mostaganem, Algeria
}

Received: 7-VII-2017 - Accepted: 9-X-2017 - Original version

Correspondence to: ab_adda@yahoo.fr

\begin{abstract}
The current study was carried out in the Cheliff watershed in Algeria, to assess the drought severity and analyze the significance of the spatiotemporal trend of annual rainfall during the period from 1914 to 2011. In this study, the rainfall series of eight stations were subject to standardized precipitation index (SPI) analysis, homogeneity tests, trend analysis and exponential smoothing in order to make a short time rainfall prediction. The results showed that the annual rainfall amount was highly dependent on latitude and elevation. Through the SPI analysis, a severe dry period closely related to the North Atlantic Oscillation (NAO) was observed during the last three decades in the Cheliff watershed, the most significant negative trend in the annual rainfall was registered above a latitude of $35^{\circ}$; indeed, above this latitude, there was a highly significant decrease in the probability of exceedance of a specific precipitation amount during the last 30 years. The major rainfall shift occurred around 1980, and according to simple exponential smoothing, the area will witness relative rainfall stability below a latitude of $35^{\circ}$ and a small increase above this latitude over the next 10 years.
\end{abstract}

Key words: Drought, Standardized Precipitation Index, rainfall, trend analysis, Cheliff, Algeria.

\section{Introduction}

With the recent climate changes, water scarcity has become a matter of prime concern for any development and effective water resource management (Magadza, 2000; Mondal et al., 2012). According to Taxak et al. (2014) rainfall is one of the key climatic factors affecting the spatial and temporal water availability, thereby the importance of drought and rainfall trend analyses in studying the impacts of climate change for water resources planning and management (Haigh, 2004). In this context, drought is the most complex and least understood of all natural hazards, affecting more people than any other hazard (Wilhite, 1993), in contrast to the permanent aridity in arid areas, drought is a temporary dry period and a recurring extreme climate event over land, characterized by below normal precipitation over a period of months to years (WMO, 1975; Dai, 2011), it occurs when there is a prolonged absence, deficiency or poor distribution of precipitation compared with the normal pattern (Subash and Ram Mohan, 2011), its intensity, magnitude and duration are best characterized by analyzing long-term time series rainfall data (Kumar et al., 2012). Many indices have been developed to measure drought, such as the simple rainfall deviation and Palmer Drought Severity Index (PDSI) (Alley, 1984). The basis of drought indices mostly depends on the magnitude of the deviation from the average of a long-term rainfall series during a particular period, among these indices, the Standardized Precipitation Index (SPI) developed by McKee et al. (1995) has been widely used in recent years, due to its simplicity and effectiveness in drought monitoring. The main weakness of the SPI is its total dependence on precipitation while ignoring other parameters, such as temperature and evapotranspiration. With regard to the Mediterranean basins, as shown in this paper, the area experienced 10 of the 12 driest winter seasons since 1902 in just the last 20 years (Hoerling et al., 2012). Cook et al. (2016) concluded an 89\% likelihood that the recent eastern Mediterranean 15-year 


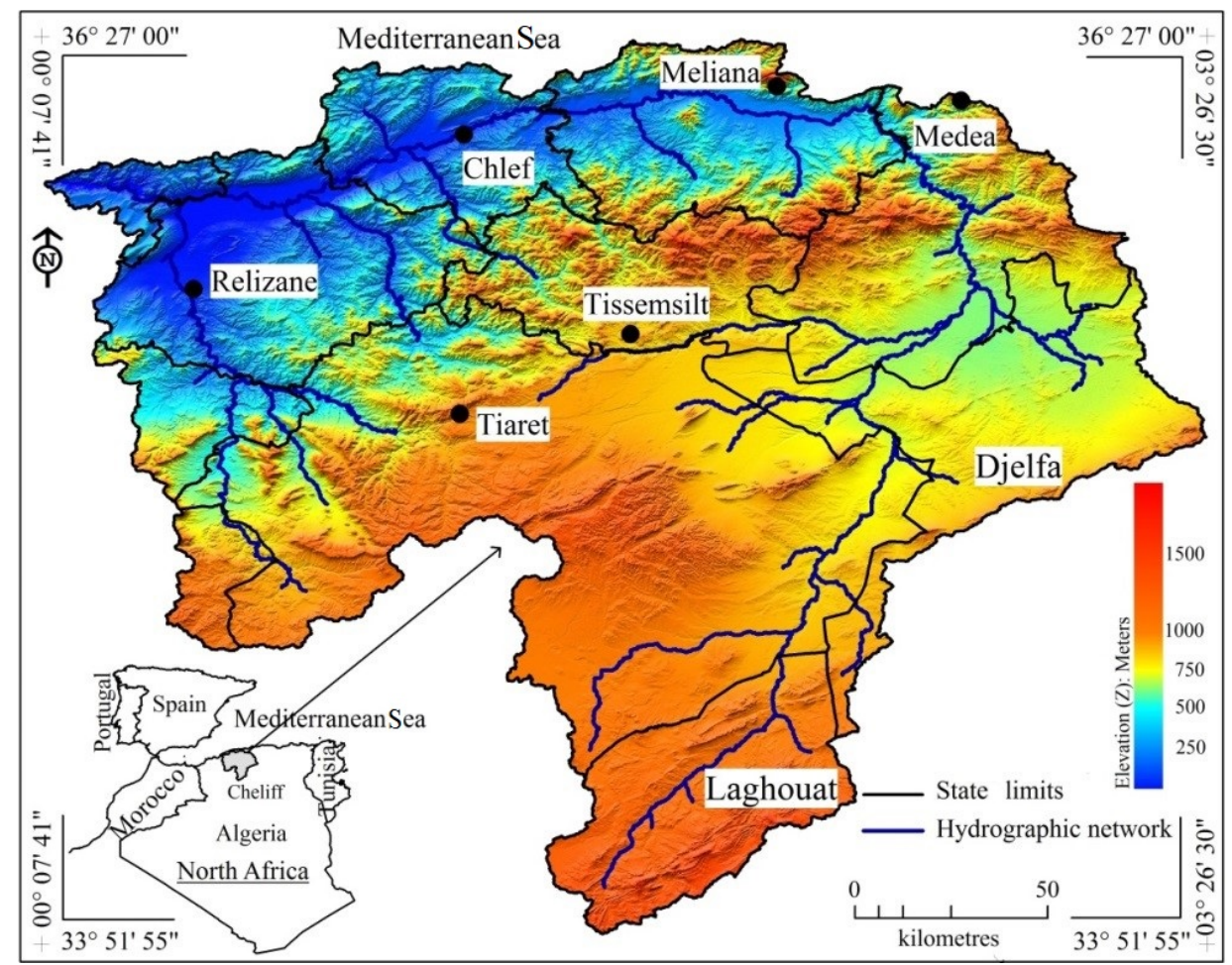

Figure 1. Location of the study area.

drought (1998-2012) is drier than any comparable period over the last 900 years, which confirms the exceptional nature of this drought relative to natural variability. Most of the climatic studies (Lamb and Peppler, 1987; Hurrell, 1995; Rodríguez-Puebla et al., 1998; Mann, 2006; Ruiz-Sinoga et al., 2012) found that the major cause of drought was highly related to the North Atlantic Oscillation (NAO). With regard to the trend leading to this severe drought, the Mediterranean has experienced a decline in precipitation since 1950 (Kelley et al., 2012), the most significant negative trends are those observed in the central and southern regions (Longobardi and Villani, 2010).

In this context, based on the general consensus about decreasing rainfall and water shortage in Algeria, the main objectives of this study conducted in the Cheliff watershed, a south Mediterranean area, are to assess the drought severity through the SPI and to analyze the long-term trends in annual precipitation over the past hundred years.

\section{Material and methods}

\subsection{Study area}

The Cheliff is the largest watershed in northern Algeria; it extends over an area of $46,600 \mathrm{~km}^{2}(2 \%$ of the country's total area) and is between $33^{\circ} 51^{\prime} 55^{\prime \prime} \mathrm{N}$ and $36^{\circ} 27^{\prime} 00^{\prime \prime} \mathrm{N}$ and $0^{\circ} 7^{\prime} 41^{\prime \prime} \mathrm{E}$ and $3^{\circ} 26^{\prime} 30^{\prime \prime} \mathrm{E}$ (Fig. 1). It is divided into three main parts; the lower, the middle and the higher Cheliff and encompasses eight states; Laghouat, Djelfa, Tiaret, Tissemsilt, Médéa, Ain-Defla, Chlef and Rélizane (Table 2). This watershed is well-differentiated morphologically, geologically and pedologically, with a rugged topography in the middle and higher Cheliff level and a flat topography in the lower Cheliff level, the elevations range from $40 \mathrm{~m}$ in the lower Cheliff level to $1,600 \mathrm{~m}$ in the higher Cheliff.

\subsection{Data analysis}

The study involved a series of rainfall data of 98 years from 1914 to 2011, collected through the eight states in the Cheliff watershed, with four missing years: 1918, 1969, 1970 and 1972. Based on the WMO normal climatological period (WMO, 1989; Arguez and Vose, 2011) and on the minimum sample size required for a normal distribution $(\mathrm{N}$ $(0,1))$, the series was divided into three periods of almost 31 years each. In order to compare the average annual rainfall between the three periods, an analysis of variance (ANOVA) was performed using a trial version of XLSTAT 2016.1. To study the rainfall behavior during the last century, the series were analyzed using the Standardized Precipitation Index (SPI) (McKee et al., 1993, 1995). The SPI was computed on an annual scale based on the shape $(\beta)$ and the scale $(\alpha)$ parameters of the gamma distribution function, indeed, as confirmed by the Kolmogorov-Smirnov test in this study, Thom (1966) found that the precipitation time series were well fitted by the Gamma distribution. The SPI was computed using an approximation provided by Abramowitz 
Table 1. Elevations and coordinates of the eight stations

\begin{tabular}{ccccccccc}
\hline & Rélizane & Chlef & Tissemsilt & Tiaret & Médéa & Meliana & Laghouat & Djelfa \\
\hline Elevation $(\mathrm{m})$ & 74 & 112 & 883 & 1023 & 935 & 740 & 775 & 1155 \\
Latitude & $35^{\circ} 43^{\prime} 45^{\prime \prime}$ & $36^{\circ} 10^{\prime} 11^{\prime \prime}$ & $35^{\circ} 36^{\prime} 04^{\prime \prime}$ & $35^{\circ} 22^{\prime} 24^{\prime \prime}$ & $36^{\circ} 15^{\prime} 59^{\prime \prime}$ & $36^{\circ} 18^{\prime} 26^{\prime \prime}$ & $33^{\circ} 47^{\prime} 50^{\prime \prime}$ & $34^{\circ} 39^{\prime} 34^{\prime \prime}$ \\
Longitude & $0^{\circ} 33^{\prime} 41^{\prime \prime}$ & $1^{\circ} 19^{\prime} 55^{\prime}$ & $1^{\circ} 48^{\prime} 27^{\prime}$ & $1^{\circ} 19^{\prime} 14^{\prime \prime}$ & $2^{\circ} 44^{\prime} 59^{\prime}$ & $2^{\circ} 13^{\prime} 28^{\prime}$ & $2^{\circ} 52^{\prime} 10^{\prime \prime}$ & $3^{\circ} 15^{\prime} 54^{\prime \prime}$ \\
\hline
\end{tabular}

and Stegun (1972) that converts cumulative probability to the standard normal random variable $\mathrm{Z}$ (Equations 1 to 9 ).

$$
\begin{array}{r}
S P I=-\left(t-\frac{c_{0}+c_{1} t+c_{2} t^{2}}{1+d_{1} t+d_{2} t^{2}+d_{3} t^{3}}\right) \\
\text { if } 0 \leq H(x) \leq 0.5 \\
S P I=+\left(t-\frac{c_{0}+c_{1} t+c_{2} t^{2}}{1+d_{1} t+d_{2} t^{2}+d_{3} t^{3}}\right) \\
\text { if } 0.5<H(x) \leq 1
\end{array}
$$

where:

$$
\begin{gathered}
t=\sqrt{\ln \left(\frac{1}{H(x)^{2}}\right)} \text { if } 0 \leq H(x) \leq 0.5 \\
t=\sqrt{\ln \left(\frac{1}{1-H(x)^{2}}\right)} \text { if } 0.5<H(x) \leq 1
\end{gathered}
$$

Since the gamma distribution is not defined for $x=0$ (no rainfall event), and the probability of zero precipitation $\mathrm{q}=$ $\mathrm{P}(x=0)$ being positive, the cumulative probability becomes (Edwards and McKee, 1997):

$$
\begin{gathered}
H(x)=q+(1-q) G(x) \\
G(x)=\frac{\int_{0}^{x} x^{\alpha-1} e^{-\frac{x}{\beta}} d x}{\beta^{\alpha} \Gamma(\alpha)} \\
\beta=\frac{1+\sqrt{1+\frac{4 U}{3}}}{4 U} \\
\alpha=\frac{\bar{x}}{\beta} \\
U=\ln (\bar{x})-\frac{\Sigma \ln (x)}{n}
\end{gathered}
$$

$c_{0}, c_{1}, c_{2}, d_{1}, d_{2}, d_{3}$ are constants equal to: $c_{0}=2.515517$; $c_{1}=0.802583 ; c_{2}=0.010328 ; d_{1}=1.432788 ; d_{2}=$ $0.189269 ; d_{3}=0.001308$. Positive SPI values indicate greater than median precipitation, and negative values indicate less than median precipitation. Because the SPI is normalized, wetter and drier climates can be represented in the same way, and wet periods can also be monitored using the SPI (Bordi and Sutera, 2007; Kostopoulou et al., 2017).

Equations 6, 7, 8 and 9 were computed using EXCEL software. The SPI drought classification (Table 2) was suggested by McKee et al. (1993). In order to test the reliability of the SPI results and to detect the shifts in
Table 2. Elevations and coordinates of the eight stations

\begin{tabular}{cc}
\hline SPI values & Drought category \\
\hline 2.00 and above & Extremely wet \\
1.50 to 1.99 & Very wet \\
1.00 to 1.49 & Moderately wet \\
-0.99 to 0.99 & Near normal \\
-1.00 to -1.49 & Moderately dry \\
-1.50 to -1.99 & Severely dry \\
-2.00 and less & Extremely dry \\
\hline
\end{tabular}

rainfall patterns, if any, the Pettitt (1979) and Buishand (1984) homogeneity tests were applied. The Pettitt test is a nonparametric test that requires no hypothesis about the distribution of the data. It is an adaptation of the rank-based Mann-Whitney test that allows the time at which the break occurs in hydrological or climate series with continuous data to be identified. In this test, Pettitt (1979) described the null hypothesis $(H 0)$ as being that the variable $\mathrm{T}$ follows a distribution that has the same location parameter (no change), and the alternative hypothesis $(\mathrm{Ha})$ as being that at a time $t$ there is a change of distribution. The Buishand test is a parametric test, applied for a series with at least 10 values, it requires the data to be normally distributed. This test is used to detect a change in the mean by studying the cumulative deviation from the mean. According to Buishand (1984) the null hypothesis $(H 0)$ is that the data are homogenous and normally distributed and the alternative hypothesis $(\mathrm{Ha})$ is that there is a date at which a change occurs in the mean. According to Toreti et al. (2011), the comparison of detected break points by several tests gives robust results avoiding overestimation. The homogeneity tests were followed by a trend analysis using the Mann-Kendall test (Mann, 1945). The Mann-Kendall statistic $S$ is given by:

$$
S=\sum_{i=1}^{n-1} \sum_{j=i+1}^{n} \operatorname{sgn}\left(x_{j}-x_{i}\right)
$$

The associated variance is calculated as:

$$
V(S)=\frac{1}{18}\left[n(n-1)(2 n+5)-\sum_{k=1}^{m} t_{p}\left(t_{p}-1\right)\left(2 t_{p}+5\right)\right]
$$

where: $s g n$ is the signum function, $m$ is the number of the tied groups in the data set and $t_{p}$ is the number of data points in the $p^{t h}$ tied group.

The statistic $S$ is approximately normally distributed if 
the following Z-transformation is employed:

$$
Z(S)=\frac{S-1}{\sqrt{(V(S)}} S>0 ; 0 \text { if } S=0 ; \frac{S+1}{\sqrt{V(S)}} \text { if } S<0
$$

Positive $Z(S)$ indicates an increasing trend and negative $Z(S)$ indicates a decreasing trend.

Both, homogeneity and Mann-Kendall tests are widely used in time series analysis and allow the detection of any possible changes in the rainfall patterns. The influence of the North Atlantic Oscillation (NAO) (Jones et al., 1997) on the rainfall regimes was tested through the correlation coefficient between SPI and NAO time series. Following the SPI analysis, the series were compared in terms of rainfall probability of exceedance using the gamma distribution. Finally, the series relative to the eight states were subject to simple (single) exponential smoothing and forecasting model $\left(S_{t}\right)$, in order to make a short time (10-year) rainfall prediction. The model is useful when the data have no trend (Fildes et al., 1997; Kalekar, 2004), in this case, the data are assumed to be relatively constant with random errors causing fluctuations (Chernick, 1972). The simple exponential smoothing is calculated according to Equation 10 for any time period $t$.

$$
S_{t}=\alpha \times X_{t}+(1-\alpha) \times S_{t-1} \quad 0<\alpha \leq 1, t \geq 3
$$

Depending on the value of $\alpha$ parameter ranging between 0 and 1 , each smoothed value is the weighted average of the previous observations and the best value of $\alpha$ is that resulting in the smallest mean squared errors $(M S E)$. In this model, all the subsequent values are highly dependent on the initial value of $S_{t}$, calculated usually according to Ostertagova and Ostertag (2011) as the average of the first five or six observations. The performance of the single exponential smoothing was then assessed using the tracking signal (TS) (Equation 14) (Mahadevan, 2009).

$$
T S=S F E / M A D
$$

where $S F E$ is the Sum of Forecast Errors and $M A D$ is the Mean Absolute Deviation

$$
\begin{gathered}
S F E=\sum_{i=1}^{n} \epsilon_{t} \quad \text { with } \epsilon_{t}=D_{t}-F_{t} \\
M A D=\frac{1}{n} \sum_{i=1}^{n}\left|\epsilon_{t}\right|
\end{gathered}
$$

where $\epsilon_{t}$ is the difference between the demand $\left(D_{t}\right)$ and the forecast $\left(F_{t}\right)$ for a period $\mathrm{t}$.

The most common boundary of the $T S$ is \pm 3 standard deviations (3.75 MAD) (Brown, 1959; McClain, 1988; Kachru, 2007; Li, 2007), if the tracking signal is greater than +3.75 , the forecast tends to exceed the current and if it is less than -3.75 , the forecast tends to be below the current, and beyond \pm 3.75 the forecast becomes biased.

\section{Results}

The spatial distribution of the annual rainfall showed that the rainfall variability was highly dependent, first on latitude and secondly on elevation. The amount of rainfall through the three periods increased gradually from south to north, especially above a latitude of $35^{\circ}$ and from low to high elevation, particularly above $700 \mathrm{~m}$. In this context, $48 \%$ of the annual rainfall in the Cheliff watershed fell above a latitude of $36^{\circ}, 34 \%$ between a latitude of $35^{\circ}$ and $36^{\circ}$ and only $19 \%$ of the annual rainfall fell below a latitude of $35^{\circ}$; the highest annual precipitations were observed respectively in the state of Meliana, Médéa, Tiaret and Tissemsilt. Rélizane and Chlef, despite their proximity to the Mediterranean Sea, registered low rainfall due to their low elevation, whereas in Laghouat and Djelfa, in spite of their high elevation, the rainfall limiting factor was the low latitude (Fig. 2).

Over the last hundred years, the annual rainfall in the Cheliff watershed has undergone very significant variations, the highest variability occurred above a latitude of $35^{\circ}$. Indeed, in comparison to the first (1914/1946) and the second period (1947/1979), the third period (1980/2011) was significantly less rainy. The previously very wet states, such as Meliana, Médéa, Tiaret and Tissemsilt, lost an average rainfall ranging between 100 and $200 \mathrm{~mm}$ during the third period (1980/2011) (Fig. 2).

As shown by high standard deviations, ranging between a minimum of 35 and a maximum of $125 \mathrm{~mm}$ (Fig. 3a), the precipitations were highly unstable in the Cheliff watershed during the first period (1914/46). During the second period (1947/79), the annual rainfall was more stable with relatively low standard deviations ranging between 25 and $65 \mathrm{~mm}$, indicating a stable wet period (Fig. 3b), and between 25 and 95 $\mathrm{mm}$ during the third period (1980/2011), suggesting a stable dry period in comparison to the two preceding periods (Fig. $3 c)$.

According to ANOVA results (Table 3), the differences were highly significant $(p<0.001)$ between the three periods in Chlef and Tiaret, whereas, in the second period, rainfall was only significantly different $(\mathrm{p}<0.001)$ from the third period in Rélizane, Médéa and Meliana. However, no significant differences $(p>0.05)$ between the precipitation averages were observed below a latitude of $35^{\circ}$, i.e. Djelfa and Laghouat. Finally, in terms of total annual rainfall, the three periods showed highly significant differences $(\mathrm{p}<0.001)$.

The long-term precipitation patterns in the Cheliff watershed were identified through the 12-month (yearly) SPI (Fig. 4). The SPI showed different behaviors in close relationship with the rainfall variability, in the normally dry area at below a latitude of $35^{\circ}$ (Laghouat and Djelfa) the SPI showed no significant pattern, only a continuous alternation between very short dry and wet periods (Fig. 4a and 4b), especially Laghouat at below $34^{\circ}$, which illustrates a climatic stability and confirms the dry nature of the area. In contrast to the dry area, the SPI showed an alternation of clearly longer dry and wet periods in the area above a latitude of $35^{\circ}$; above 

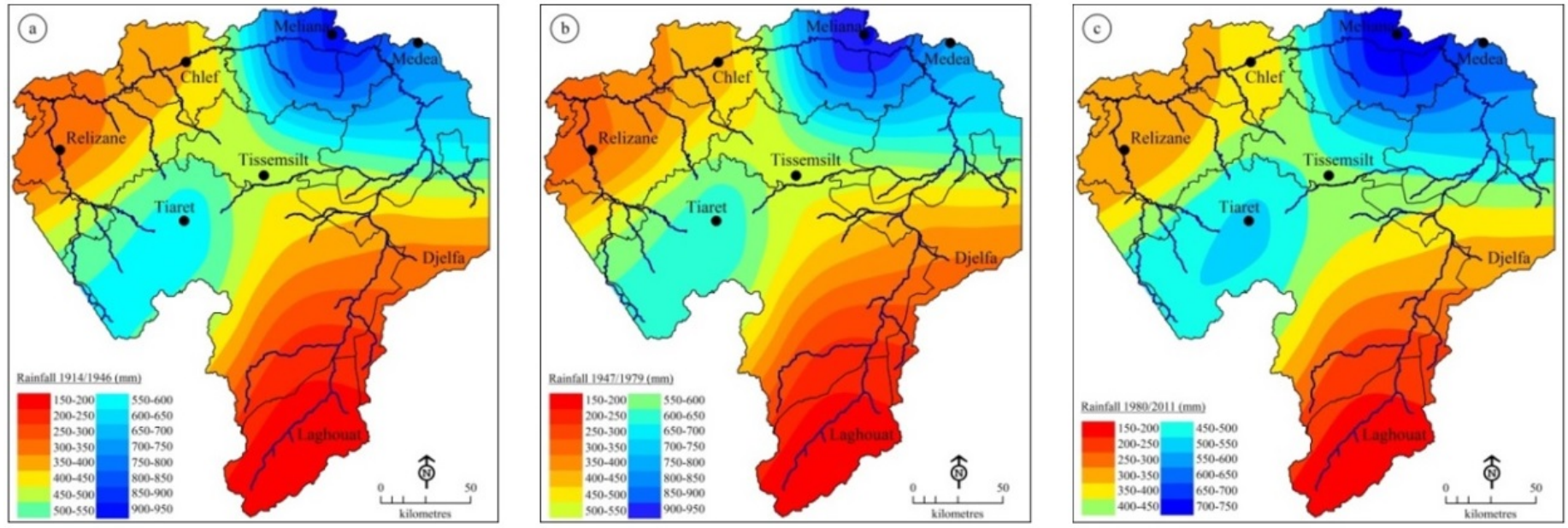

Figure 2. Annual rainfall distribution in the Cheliff watershed (a) 1914/1946, (b) 1947/1979, (c) 1980/2011.
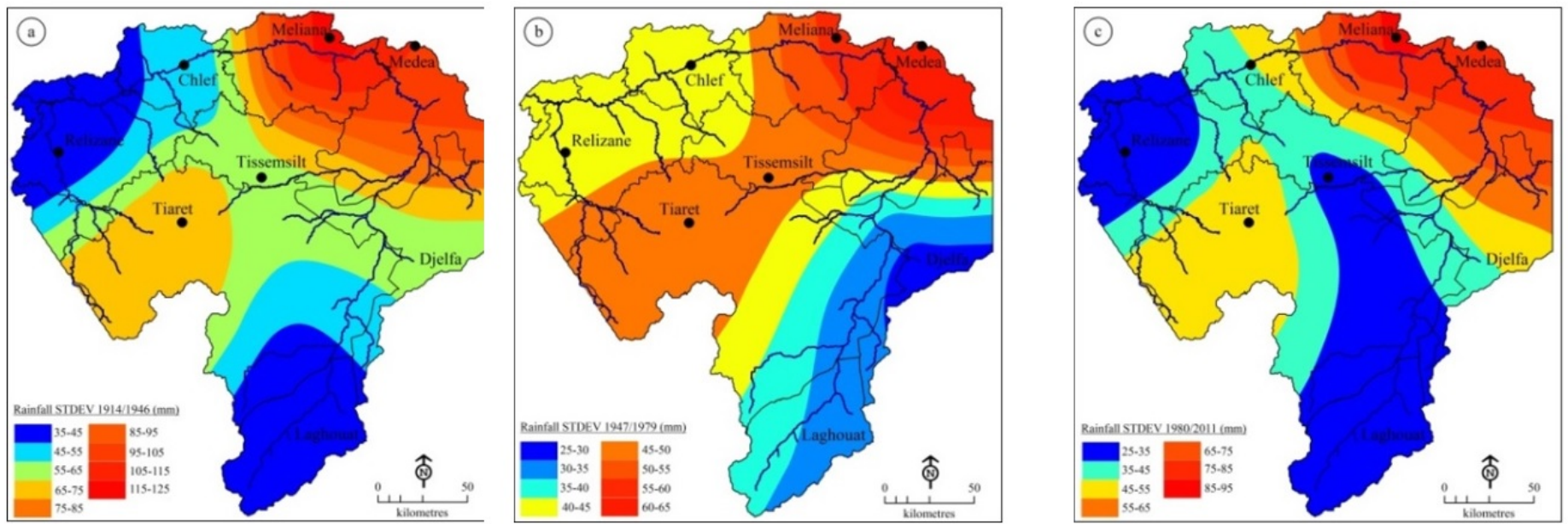

Figure 3. Rainfall standard deviation maps (a) 1914/1946, (b) 1947/1979, (c) 1980/2011.

Table 3. Results of the analysis of variance between the three periods

\begin{tabular}{cccccccccc}
\hline & Rélizane & Chlef & Tissemsilt & Tiaret & Laghouat & Djelfa & Médea & Meliana & Total \\
\hline $1914 / 46$ & $338^{a}$ & $398^{a}$ & $463^{a}$ & $572^{a}$ & $184^{a}$ & $320^{a}$ & $700^{a}$ & $907^{a}$ & $3883^{a}$ \\
$1947 / 79$ & $347^{a}$ & $434^{b}$ & $521^{b}$ & $630^{b}$ & $185^{a}$ & $337^{a}$ & $741^{a}$ & $951^{a}$ & $4145^{b}$ \\
$1980 / 11$ & $302^{b}$ & $364^{c}$ & $442^{a}$ & $509^{c}$ & $189^{a}$ & $314^{a}$ & $606^{b}$ & $744^{b}$ & $3470^{c}$ \\
P-value & $<0.001$ & $<0.001$ & $<0.001$ & $<0.001$ & 0.825 & 0.119 & $<0.001$ & $<0.001$ & $<0.001$
\end{tabular}

${ }^{*}$ The indices $a, b$ and $c$ refer to the three average rainfall periods in each state. The non-significantly different averages are assigned the same index, whereas the significantly different averages are assigned different indices.

this latitude the longest and most severe dry period occurred in the state of Rélizane at an elevation of $74 \mathrm{~m}$ (Fig. 4c), indeed, after a continuous wet period of 12 years (1947-1959) the whole area of the lower Cheliff underwent a dry period of almost 52 years from 1959 to 2011, excluding a few scattered normal years. With the increasing elevation from west to east, the dry period became relatively shorter, indeed, according to the SPI results, after an oscillatory period of 27 years between 1914 and 1940, the state of Chlef, at an elevation of $112 \mathrm{~m}$, was subject to two clearly distinct periods
(Fig. 4d); a wet period of 37 years from 1942 to 1978, followed by a normal period of eight years, according to the SPI scale, and a severe dry period of 20 years (1987-2006). The same pattern was shown at greater elevations (above $700 \mathrm{~m}$ ), indeed, the four states of higher Cheliff showed an oscillatory period, followed by a wet period of 29 years (1947-1975) in the states of Tiaret and Tissemsilt, 43 years in Médéa (1933$1975)$ and 48 years in Meliana (1928-1975), then a normal period of five years from 1975 to 1980 , followed by a very long dry period of almost 26 years (1980-2006) in the four 

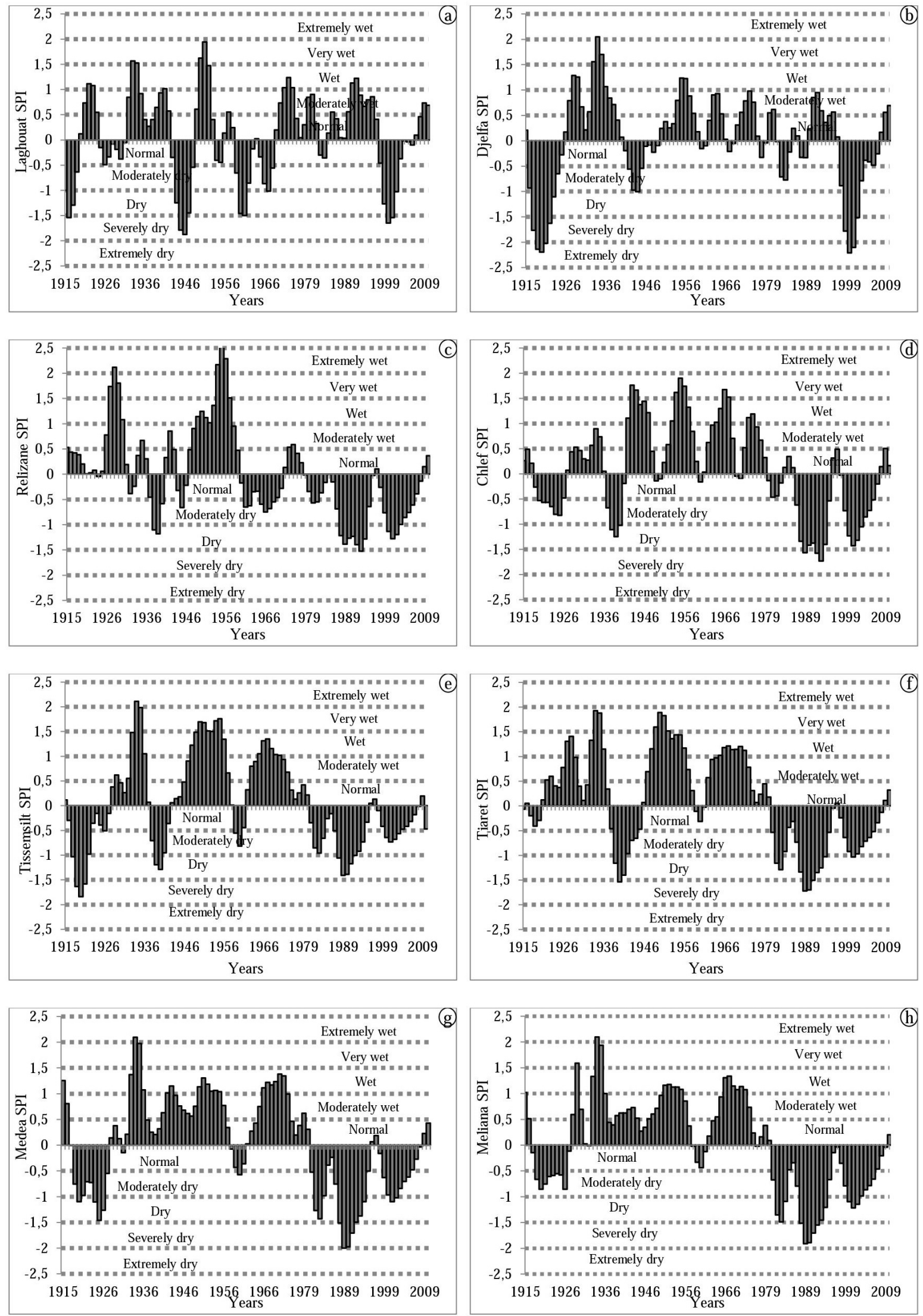

Figure 4. Standardized precipitation index (SPI), (a) Laghouat, (b) Djelfa, (c) Rélizane, (d) Chlef, (e) Tissemsilt, (f) Tiaret, (g) Médéa and (h) Meliana. 

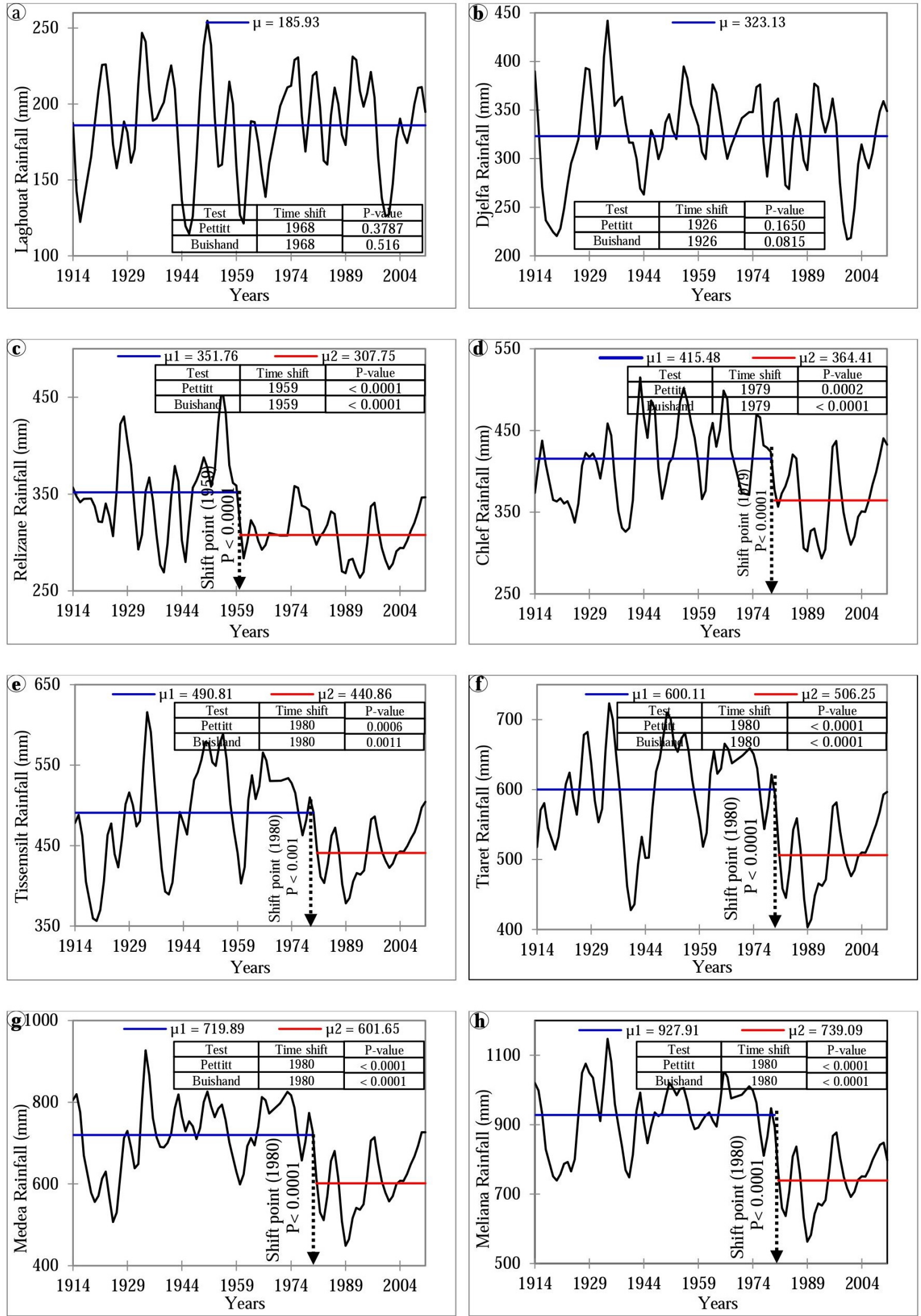

Figure 5. Homogeneity analysis and shift detection (a) Laghouat, (b) Djelfa, (c) Rélizane, (d) Chlef, (e) Tissemsilt, (f) Tiaret, (g) Médéa and (h) Meliana. 
Table 4. Correlation coefficient between NAO and SPI in the Cheliff Watershed. Bold types indicate a significant correlation at $\alpha=5 \%$.

\begin{tabular}{cccccccccc}
\hline \multicolumn{10}{c}{ SPI } \\
\hline \multirow{2}{*}{ NAO } & Rélizane & Chlef & Tissemsilt & Tiaret & Laghouat & Djelfa & Médéa & Meliana \\
& $1914 / 2011$ & $\mathbf{- 0 . 3 5}$ & $\mathbf{- 0 . 5 1}$ & $\mathbf{- 0 . 3 7}$ & $\mathbf{- 0 . 4 1}$ & 0.15 & -0.11 & $\mathbf{- 0 . 5 3}$ & $\mathbf{- 0 . 5 6}$ \\
& $1980 / 2011$ & $\mathbf{- 0 . 6 9}$ & $\mathbf{- 0 . 6 9}$ & $\mathbf{- 0 . 8 8}$ & $\mathbf{- 0 . 8 7}$ & 0.05 & 0.04 & $\mathbf{- 0 . 8 8}$ & $\mathbf{- 0 . 8 7}$ \\
\hline
\end{tabular}

Table 5. Mann-Kendall trend test of the rainfall in the Cheliff watershed.

\begin{tabular}{ccccccccc}
\hline & Laghouat & Djelfa & Rélizane & Chlef & Tissemsilt & Tiaret & Médea & Meliana \\
\hline $\mathrm{Z}(\mathrm{S})$ & 0.64 & -0.21 & -4.14 & -1.59 & -1.10 & -2.99 & -2.46 & -4.39 \\
P-value & 0.522 & 0.834 & $<0.0001$ & 0.111 & 0.271 & 0.003 & 0.014 & $<0.0001$ \\
Relative change & 0 & 0 & $-12.5 \%$ & $-12.3 \%$ & $-10.2 \%$ & $-15.6 \%$ & $-16.4 \%$ & $-20.35 \%$ \\
\hline
\end{tabular}

states (Fig. 4e, 4f, 4g, 4f).

Above a latitude of $35^{\circ}$, the precipitations were highly affected by the North Atlantic Oscillation (NAO), indeed as shown by the correlation coefficient (Table 4) there was a highly significant negative correlation between SPI and NAO in Rélizane, Chlef, Tissemsilt, Tiaret, Médéa and Meliana, whereas the dry area below a latitude of $35^{\circ}$ was less sensitive to the NAO, as indicated by low and statistically nonsignificant correlation coefficients registered in Laghouat and Djelfa.

Considering the SPI results, the homogeneity analysis did not show any change below a latitude of $35^{\circ}$ in Laghouat and Djelfa, indeed the Buishand (1984) and Pettitt (1979) tests, did not detect any significant shift, only an alternation between dry and wet years around a respective mean of 186 $\mathrm{mm}$ in Laghouat and $323 \mathrm{~mm}$ in Djelfa (Fig. 5a, 5b). The remaining states above a latitude of $35^{\circ}$ showed a highly significant $(\mathrm{p}<0.001)$ decrease in the amount of rainfall according to the Buishand (1984) and Pettitt (1979) tests. The early shift occurred in Rélizane in 1959, thus, the lower Cheliff lost a yearly average of almost $50 \mathrm{~mm}$ after this year (Fig. 5c); in the state of Chlef the shift occurred later, during 1979, after this year there was also a decrease of $50 \mathrm{~mm}$ in the middle Cheliff (Fig. 5d). In the four remaining states of higher Cheliff, Tissemsilt, Tiaret, Médéa and Meliana, the shift occurred, according to both the Buishand and Pettitt tests, in 1980. In this area, the average yearly loss was around $50 \mathrm{~mm}$ in Tissemsilt (Fig. 5e) and $90 \mathrm{~mm}$ in Tiaret (Fig. 5f). At a higher latitude of above $36^{\circ}$, the average yearly loss was more important around $120 \mathrm{~mm}$ in Médéa (Fig. 5g) and almost $200 \mathrm{~mm}$ in Meliana (Fig. 5h).

Above a latitude of $35^{\circ}$, all the stations showed a high negative $\mathrm{Z}(\mathrm{S})$ (Table 5), signifying a decreasing trend, the most significant negative trends were those observed in Meliana ( $\mathrm{p}<0.0001)$, Rélizane $(\mathrm{p}<0.0001)$, Tiaret $(\mathrm{p}<$ $0.01)$ and Médéa $(\mathrm{p}<0.05)$. The trend observed in the northern part of this area was further reflected by the relative change, which decreased by $10 \%$ to more than $20 \%$ (Table 5). The same finding was mentioned by Miranda et al. (2011). In accordance with the homogeneity tests, the lowest non-significant $Z s(S)$ were observed in Djelfa and Laghouat, meaning the absence of trend below a latitude of $35^{\circ}$.
In order to confirm the shift that occurred after 1980, the three periods (1914/1946, 1947/1979 and 1980/2011) were compared in terms of probability of exceedance of a specific precipitation amount. The results showed no significant change in terms of probabilities in Laghouat (Fig. 6a), and a small decrease in Djelfa (Fig. 6b). In the six remaining states, the observed probabilities of the third period (1980/2011) were much lower than the first (1914/1946) and the second periods (1947/1979). In terms of extreme rainfall, the probability of observing rainfall of more than $345 \mathrm{~mm}$ decreased from 0.55 during the first period to 0 during the third period in the lower Cheliff (Rélizane). In the middle Cheliff (Chlef) the probability of an amount of $434 \mathrm{~mm}$ dropped from 0.51 during the second period to 0 during the last period (Fig. 6d). In the higher Cheliff the probabilities of a yearly average of $495 \mathrm{~mm}$ in Tissemsilt, $595 \mathrm{~mm}$ in Tiaret, $725 \mathrm{~mm}$ in Médéa and $895 \mathrm{~mm}$ in Meliana dropped respectively from $0.68,0.78,0.55$ and 0.85 during the second period to 0 after the shift of 1980 (Fig. 6e, 6f, 6g, 6h).

The near future rainfall tendencies in the Cheliff watershed were forecasted using single exponential smoothing since this model is suitable for short-range forecasting of data with no trend and based on the parameter $\alpha(0<\alpha \leq 1)$, a 10year forecasting period was chosen $(2011 / 2021)$ based on the simple exponential smoothing of the whole 94-year period for Laghouat and Djelfa, 50 years for Rélizane (1959/2011) and the last 30-year period (1980/2011) for Chlef, Tissemsilt, Tiaret, Médéa and Meliana, the $\alpha$ parameter was chosen to be equal to 0.5 . The results (Table 5) showed that the expected averages for the next 10 years $(2011 / 2021)$ in the driest area of the Cheliff watershed i.e. Laghouat $(200 \pm 69$ $\mathrm{mm})$, Rélizane $(341 \pm 46 \mathrm{~mm})$ and Djelfa $(347 \pm 83 \mathrm{~mm})$ were relatively close to the observed current averages, 186, 302 and $323 \mathrm{~mm}$ respectively; indeed, the highest R2 between the observed and forecasted rainfall was recorded in this area, which indicates a relative rainfall stability, while the forecasted averages in the wet area (Chlef, Tissemslit, Tiaret, Médéa and Meliana) were at least $50 \mathrm{~mm}$ higher than the observed means (Table 6) signifying an increasing rainfall tendency.

The forecast accuracy was assessed using the tracking signal (TS), according to which the best forecasts were respectively those related to Laghouat, Djelfa, Rélizane, Chlef, 

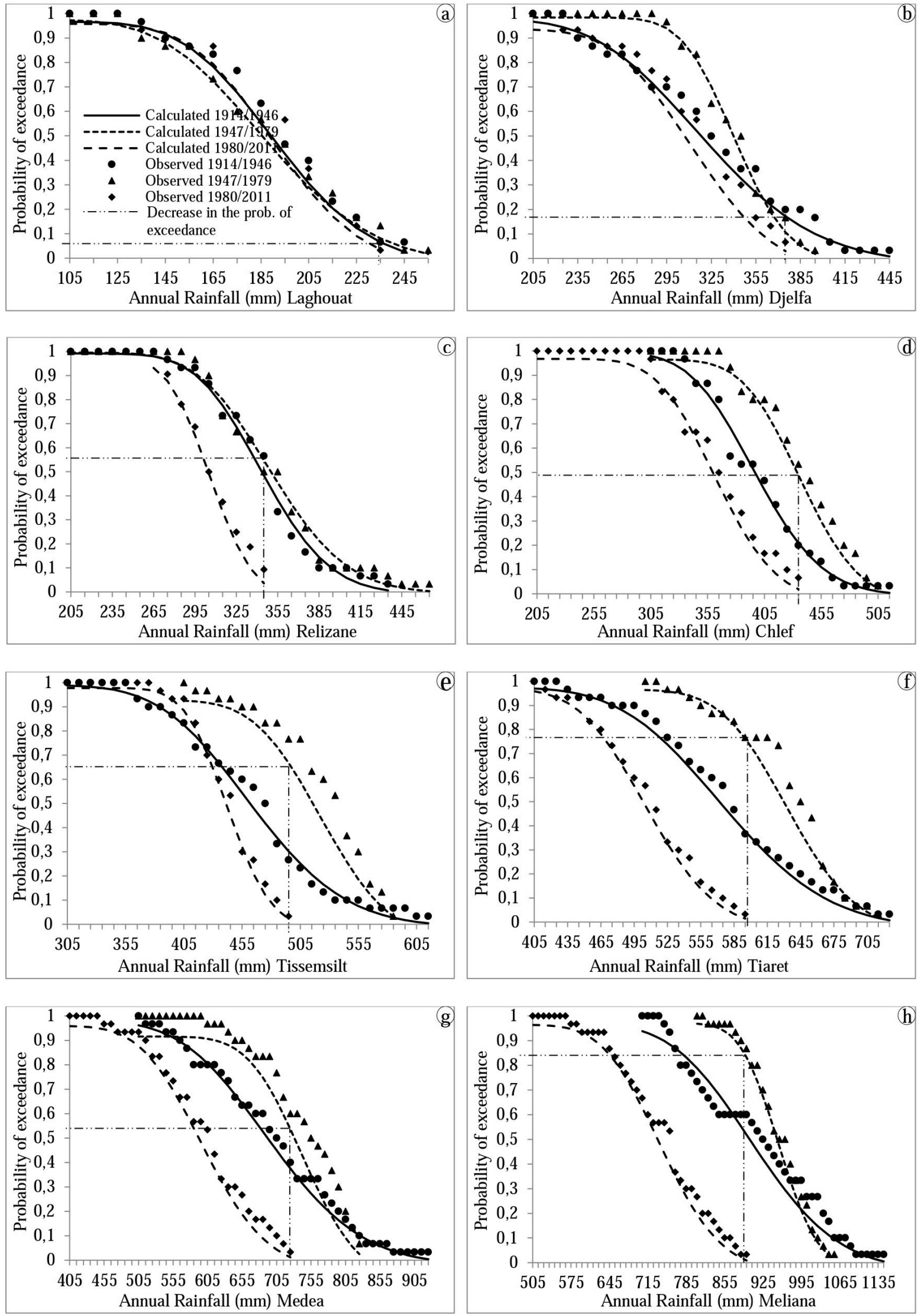

Figure 6. Cumulative density function and comparison between the probabilities of exceedance during the three periods (a) Laghouat, (b) Djelfa, (c) Rélizane, (d) Chlef, (e) Tissemsilt, (f) Tiaret, (g) Médéa and (h) Meliana. 
Table 6. Exponential smoothing and prediction $(\alpha$ parameter $=0.5)$

\begin{tabular}{ccccccccc}
\hline & Laghouat & Djelfa & Rélizane & Chlef & Tissemsilt & Tiaret & Médea & Meliana \\
\hline Prediction period & $1914 / 11$ & $1914 / 11$ & $1959 / 11$ & $1980 / 11$ & $1980 / 11$ & $1980 / 11$ & $1980 / 11$ & $1980 / 11$ \\
\hline $\mathrm{R}^{2}$ & 0.23 & 0.41 & 0.34 & 0.22 & 0.18 & 0.19 & 0.20 & 0.21 \\
Forecasted & 200 & 347 & 341 & 427 & 494 & 585 & 713 & 816 \\
95\% error of estimation & 69 & 83 & 46 & 86 & 63 & 103 & 153 & 179 \\
Real average & 186 & 322 & 302 & 364 & 442 & 509 & 606 & 744 \\
\hline
\end{tabular}

Tiaret, and Tissemsilt. Indeed, as shown in Fig. 7a, 7b and 7c, except for a few points below the TS lower limit, the majority of the values were comprised between the TS upper and lower limits \pm 4 , which indicates a good validity of the exponential forecast, whereas the worst exponential forecasts were those related to the highly wet areas i.e. Médéa and Meliana. In these areas, as shown in Fig. 7d, most of the points were below the lower limit -4 , indicating that the forecasted values were below the current observations, which suggests a highly biased forecast. Among the forecasted values, we note the total absence of overestimated values (above the upper limit +4 ) throughout the Cheliff watershed. The results also showed that the tracking signal (TS) was closely related to the standardized precipitation index (SPI) with an $R^{2}$ varying between 0.69 and 0.76 (Fig. 7), in this context, it was remarkable that the worst forecasts were always related to the exceptionally dry years with an SPI lower than -1 .

\section{Discussion}

The Cheliff watershed is a typical Mediterranean area distinguished by hot, dry summers and relatively rainy winters, except for the area below a latitude of $35^{\circ}$ Laghout and Djelfa with an arid to semi-arid continental climate. Temporally, all around the Cheliff watershed, $41 \%$ of the total precipitations fall during winter, $28 \%$ during spring, $26 \%$ during autumn and only 5\% during the summer; spatially the annual rainfall was highly dependent primarily on latitude and secondly on elevation, $80 \%$ of the total precipitations were recorded above a latitude of $35^{\circ}$ and only $20 \%$ below this latitude. As reported in the Mediterranean area by many authors (Longobardi and Villani, 2010; Arnone et al., 2013), a strong negative trend was observed in the northern part of the Cheliff watershed, the main climatic shift according to the SPI and homogeneity analysis occurred above a latitude of $35^{\circ}$ around 1980. Indeed according to Conversi et al. (2010), the major rainfall shift in the Mediterranean area occurred at the end of the 1980s. To this effect, the $1947 / 1979$ rainfall was significantly $(\mathrm{p}<0.001)$ superior to the 1980/2011 rainfall above a latitude of $35^{\circ}$, whereas below this latitude there was no difference, the decrease in rainfall amount during the last period (1980/2011) was accompanied by a high decrease in the probabilities of exceedance of the different rainfall categories. To confirm the rainfall shift, the observed precipitations were divided into five quintiles $(\leq \mathrm{Q} 1=$ very dry years; between Q1 and Q2 = dry years; between Q2 and $\mathrm{Q} 3$ = normal years; between $\mathrm{Q} 3$ and Q4 = wet years and > Q4 = very wet years) the results were strongly concordant with those of the SPI, indeed the results showed that from 1980 to $2011,81 \%$ of the years in Meliana, $75 \%$ of the years in Médéa and Tiaret, $69 \%$ of the years in Tissemsilt, $66 \%$ of the years in Rélizane and $59 \%$ of the years in Chlef were among the dry to very dry years, and $0 \%$ among the very wet years in all the six states. Regarding Djelfa and Laghouat, as identified by the SPI, the Pettitt and Buishand tests, the percentages were almost evenly distributed between the different classes, $44 \%$ in Djelfa and $38 \%$ of the years in Laghouat were dry to very dry, whereas, $34 \%$ and $47 \%$ respectively were distributed between wet to very wet years, which confirms the climatic stability below the latitude of $35^{\circ}$.

In this Mediterranean area, as indicated by the strong inverse correlation between SPI and NAO, the decrease in the rainfall amount above a latitude of $35^{\circ}$ was largely influenced by the North Atlantic Oscillation, the influence became stronger when only the last period (1980/2011) was considered, indeed as reported by Lamb and Peppler (1987) there was a strong inverse relationship between the NAO and precipitation in northern Morocco, only $300 \mathrm{~km}$ west of the Cheliff watershed, this observation was also reported by many other authors (Hurrell, 1995; MunozDiaz and Rodrigo, 2004; Brandimarte et al., 2011; LopezMoreno et al., 2011; Bonaccorso et al., 2015). It is therefore imperative to focus on the NAO probabilities evolution if agricultural purposes are considered.

Although according to Kostopoulou et al. (2017) annual precipitation is expected to decrease in the Mediterranean region, the single exponential smoothing of the next ten years showed variable forecasts. In the driest area of the Cheliff watershed, the forecasted rainfall was very close to the observed current average, indicating a relative rainfall stability and thus the persistence of drought in this area, while the forecasted averages in the wet area above a latitude of $35^{\circ}$ were slightly higher than the observed means signifying a small increasing rainfall tendency, indeed according to Kutzbach et al. (2014) and Buric et al. (2015), a slight increasing tendency towards rainfall events is suggested in the Mediterranean region. 

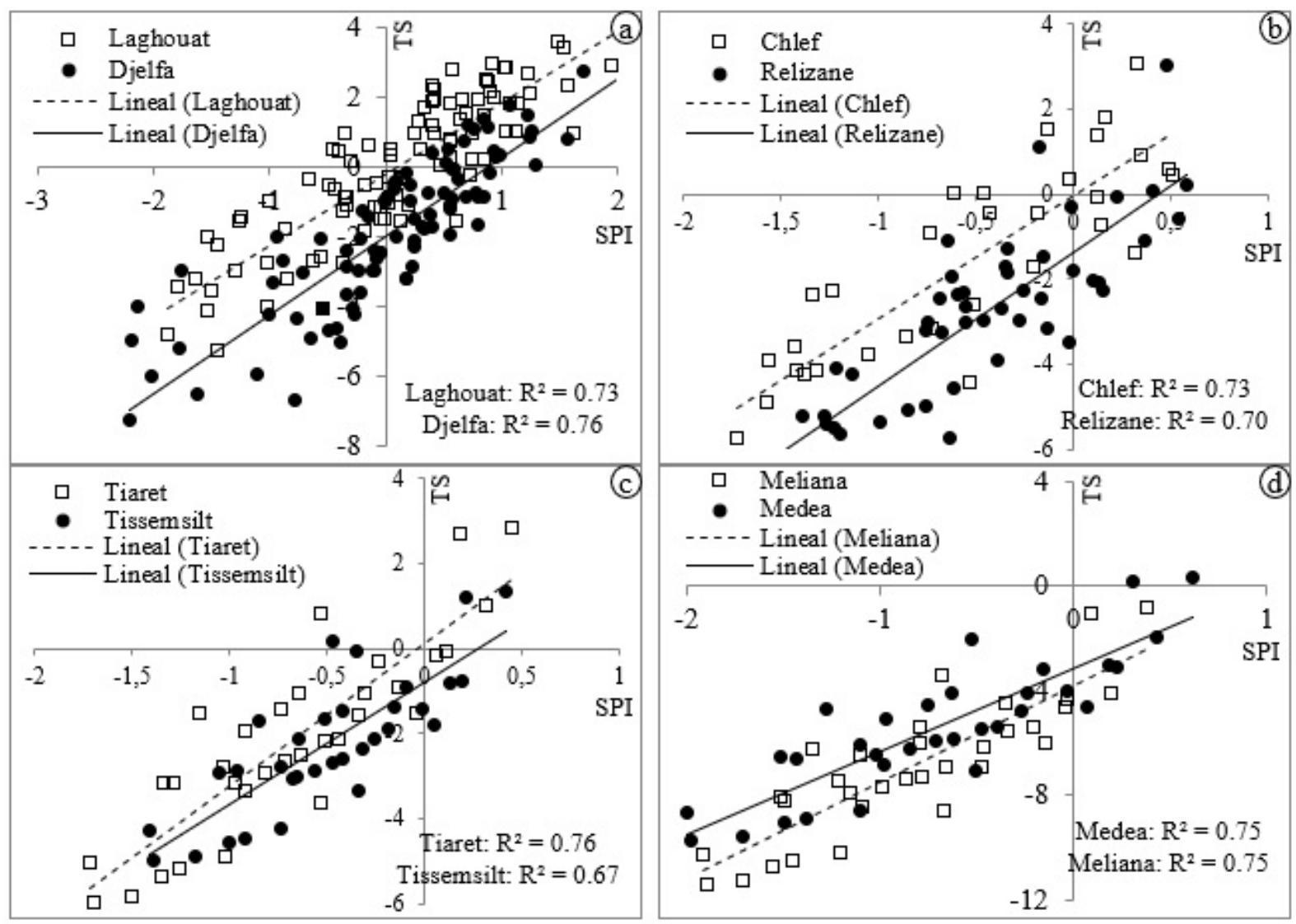

Figure 7. Tracking signal (TS) vs. SPI: (a) Laghouat, Djelfa (b) Rélizane, Chlef, (c) Tissemsilt, Tiaret and (d) Médéa, Meliana.

\section{Conclusion}

This study analyzed the Cheliff watershed rainfall based on the data recorded over 94 years in eight stations. When attempting to detect any potential changes in annual rainfall over an area of $46,600 \mathrm{~km}^{2}$ in the south of the Mediterranean through these records, a strong negative trend with respect to the northern latitudes close to the Mediterranean was detected, suggesting a successive dominant decrease in annual rainfall amounts. The SPI and the homogeneity test yielded very interesting results; after the 1980 rainfall shift, the area witnessed an intense, prolonged dry period of more than 30 years, highly affected by the positive values of the North Atlantic Oscillation. The 30-year dry period was accompanied by a strong decrease in the probabilities of exceedance of a certain rainfall amount compared to the historical wet period before 1980. Finally, the rainfall is expected to fluctuate between the stability below a latitude of $35^{\circ}$ and a slight increase above this latitude.

\section{References}

Abramowitz, M. and Stegun, I., 1972: Handbook of Mathematical Functions: with Formulas, Graphs, and Mathematical Tables, wiley, New York.
Alley, W., 1984: The Palmer Drought Severity Index: Limitations and Assumptions., J. Climate Appl. Meteor., 23, 1100-1109, dOI: http://dx.doi.org/10.1175/15200450(1984)023<1100:TPDSIL>2.0.CO;2.

Arguez, A. and Vose, R., 2011: The Definition of the Standard WMO Climate Normal. The Key to Deriving Alternative Climate Normals., Am. Meteorol. Soc., 92(6), 699-704, dOI: http://dx.doi.org/10.1175/BAMS-D-12-00155.1.

Arnone, E., Pumo, D., Viola, F., Noto, L., and La Loggia, G., 2013: Rainfall statistics changes in Sicily, Hydrol. Earth Syst. Sc., 17.

Bonaccorso, B., Cancelliere, A., and Rossi, G., 2015: Probabilistic forecasting of drought class transitions in Sicily (Italy) using Standardized Precipitation Index and North Atlantic Oscillation Index, J. Hydrol., 526, 136-150, dOI: https://doi.org/10.1016/j.jhydrol.2015.01.070.

Bordi, I. and Sutera, A., 2007: Drought Monitoring and Forecasting at Large Scale, in Rossi, G., Vega, T. and Bonaccorso, B, (ed) Methods and Tools for Drought Analysis and Management., ed. Springer, Dordrecht, pp 3-27.

Brandimarte, L., Di Baldassarre, G., Bruni, G., D'Odorico, P., and Montanari, A., 2011: Relation Between the North-Atlantic Oscillation and Hydroclimatic Conditions in Mediterranean Areas, Water Resour. Manag., 25, 1269-1279, dOI: 10.1007/s11269010-9742-5.

Brown, R., 1959: Statistical Forecasting for Inventory Control, mcGraw-Hill, USA. 
Buishand, T., 1984: Tests for detecting a shift in the mean of hydrological time series, J. Hydrol., 58, 51-69, dOI: https://doi.org/10.1016/0022-1694(84)90032-5.

Buric, D., Lukovic, J., Bajat, B., Kilibarda, M., and Zivkovic, N., 2015: Recent trends in daily rainfall extremes over Montenegro (1951-2010), Nat. Hazards Earth Syst. Sci., 15, 2069-2077, dOI:10.5194/nhess-15-2069-2015.

Chernick, M., 1972: Methods for Applying a Tracking Signal to Monitor Single Exponential Smoothing Forecasts, aMSAA, Technical Memorandum no. 140.

Conversi, A., Umani, S., Peluso, T., Molinero, J., Santojanni, A., and Edwards, M., 2010: The Mediterranean Sea Regime Shift at the End of the 1980s, and Intriguing Parallelisms with Other European Basins, PLoS One, 5(5), e10633, dOI: https://doi.org/10.1371/journal.pone.0010633.

Cook, B., Anchukaitis, K., Touchan, R., Meko, D., and E.R., C., 2016: Spatiotemporal drought variability in the Mediterranean over the last 900 years, J. Geophys. Res., 121, 2060-2074, dOI: 10.1002/2015JD023929.

Dai, A., 2011: .

Edwards, D. and McKee, T., 1997: Characteristics of 20th Century Drought in the United States at Multiple Time Series, fort Collins, Colo, USA: Colorado State University.

Fildes, R., Randall, A., and Stubbs, P., 1997: One day ahead demand forecasting in the utility industries: Two case studies, J. Oper. Res. Soc., 48, 15-24, dOI: 10.2307/3009939.

Haigh, M., 2004: Sustainable Management of Headwater Resources: the Nairobi Headwater Declaration (2002) and Beyond, Asian J. Water Environ., 1, 17-28, d24S09. doi: 10.1029/2007JD008465.

Hoerling, M., Eischeid, J., Perlwitz, J., Quan, X., Zhang, T., and Pegion, P., 2012: On the Increased Frequency of Mediterranean Drought, J. Climate, 25, 2146-2161, doi: http://dx.doi.org/10.1175/JCLI-D-11-00296.1.

Hurrell, J., 1995: Decadal Trends in the North Atlantic Oscillation: Regional Temperatures and Precipitation, Science, 269, 676679, doi: 10.1126/science.269.5224.676.

Jones, P., Jonsson, T., and Wheeler, D., 1997: Extension to the North Atlantic Oscillation using Early Instrumental Pressure Observations from Gibraltar and South-West Iceland, Int. J. Climatol., 17, 1433-1450, doi: 10.1002/(SICI)10970088(19971115)17:13<1433::AID-JOC203>3.0.CO;2-P.

Kachru, U., 2007: Production and Operations Management, ed. Excel Books, India, New Delhi.

Kalekar, P., 2004: Time series Forecasting using Holt-Winters Exponential Smoothing, Kanwal Rekhi School of Information Technology, p. 13p.

Kelley, C., Ting, M., Seager, R., and Kushnir, Y., 2012: Mediterranean precipitation climatology, seasonal cycle, and trend as simulated by CMIP5, Geophys. Res. Lett., 39, L21 703, doi: http://dx.doi.org/10.1029/2012GL053416.

Kostopoulou, E., Giannakopoulos, C., Krapsiti, D., and Karali, A., 2017: Temporal and Spatial Trends of the Standardized Precipitation Index (SPI) in Greece Using Observations and Output from Regional Climate Models., springer Atmospheric Sciences.

Kumar, M., Murthy, C., Sai, M., and Roy, P., 2012: Spatiotemporal Analysis of Meteorological Drought Variability in the Indian Region Using Standardized Precipitation Index, Meteorol. Appl., 19, 256-264, doi: 10.1002/met.277.
Kutzbach, J., Chen, G., Cheng, H., Edwards, R., and Liu, Z., 2014: Potential role of winter rainfall in explaining increased moisture in the Mediterranean and Middle East during periods of maximum orbitally-forced insolation seasonality., Clim. Dynam., 42, 1079-1095.

Lamb, P. and Peppler, R., 1987: North Atlantic Oscillation: Concept and Application, Bull. Am. Meteorol. Soc., 68, 1218-1225, doi: http://dx.doi.org/10.1175/15200477(1987)068<1218:NAOCAA > 2.0.CO;2.

Li, L., 2007: Supply Chain Management: Concepts, Techniques and Practices Enhancing the Value Through Collaboration, world Scientific Publishing Company, 372 p.

Longobardi, A. and Villani, P., 2010: Trend analysis of annual and seasonal rainfall time series in the Mediterranean area, Int. J. Climatol., 30, 1538-1546, doi: 10.1002/joc.2001.

Lopez-Moreno, J., Vicente-Serrano, S., Moran-Tejeda, E., LorenzoLacruz, J., Kenawy, A., and Beniston, M., 2011: Effects of the North Atlantic Oscillation (NAO) on combined temperature and precipitation winter modes in the Mediterranean mountains: Observed relationships and projections for the 21st century, Glob. Planet Change, 77, 62-76, doi: https://doi.org/10.1016/j.gloplacha.2011.03.003.

Magadza, C., 2000: Climate Change Impacts and Human Settlements in Africa: Prospects for Adaptation, Environ. Monit. Assess., 61, 193-205, doi: 10.1023/A:1006355210516.

Mahadevan, B., 2009: Operation Management: Theory and Practice. 1st Ed., prentice Hall, Pearson.

Mann, H., 1945: Nonparametric Tests against Trend, Econometrica, 13, 245-259, doi: 10.2307/1907187.

Mann, M., 2006: Climate Changes Over the Past Millennium: Relationships with Mediterranean Climates, Il nuovo cimento, 29, 73-80, doi: 10.1393/ncc/i2005-10223-1.

McClain, J., 1988: Dominant tracking signals, Int. J. Forecast, 4, 563-572, doi: https://doi.org/10.1016/0169-2070(88)90133-1.

McKee, T., Doesken, N., and Kleist, J., 1993: The relationship of drought frequency and duration to time scales, Am. Meteorol. Soc., pp. 179-184.

McKee, T., Doesken, N., and Kleist, J., 1995: Drought Monitoring with Multiple Time Scales. Ninth Conference on Applied Climatology, Am. Meteorol. Soc., p. 233-236.

Miranda, J., Armas, C., Padilla, F., and Pugnaire, F., 2011: Climatic Change and Rainfall Patterns: Effects on Semi-arid Plant Communities of the Iberian Southeast, J. Arid Environ., 75, 1302-1309, doi: https://doi.org/10.1016/j.jaridenv.2011.04.022.

Mondal, A., Kundu, S., and Mukhopadhyay, A., 2012: Rainfall trend analysis by Mann-Kendall Test: A Case Study of NorthEastern Part of Cuttack District, Orissa, Int. J Geo. Earth. Env. Sc., 2, 70-80.

Munoz-Diaz, D. and Rodrigo, F., 2004: Impacts of the North Atlantic Oscillation on the probability of dry and wet winters in Spain, . Clim. Res., 27, 33-43, doi:10.3354/cr027033.

Ostertagova, E. and Ostertag, O., 2011: The Simple Exponential Smoothing Model.

Pettitt, A., 1979: A Non-Parametric Approach to the Change-Point Problem, J. R. Stat. Soc., 28, 126-135, doi: 10.2307/2346729.

Rodríguez-Puebla, C., Encinas, A., Nieto, S., and Garmendia, J., 1998: Spatial and temporal patterns of annual precipitation variability over the Iberian Peninsula, Int. J. Climatol., 18, 299316, doi: 10.1002/(SICI)1097-0088(19980315)18:3<299::AIDJOC247>3.0.CO;2-L. 
Ruiz-Sinoga, J., Garcia-Marin, R., Gabarron-Galeotea, M., and Martinez-Murilloa, J., 2012: Analysis of dry periods along a pluviometric gradient in Mediterranean southern Spain, Int. J. Climatol., 32, 1558-1571, doi: 10.1002/joc.2376.

Subash, N. and Ram-Mohan, H., 2011: Trend detection in rainfall and evaluation of standardized precipitation index as a drought assessment index for rice-wheat productivity over IGR in India, Int. J. Climatol., 31, 1694-1709, doi: 10.1002/joc.2188.

Taxak, A., Murumkar, A., and Arya, D., 2014: Long term spatial and temporal rainfall trends and homogeneity analysis in Wainganga basin, Central India, Weather and Climate Extremes, 4, 50-61, doi:https://doi.org/10.1016/j.wace.2014.04.005.

Thom, H., 1966: Some Methods of Climatological Analyses. World Meteorological Organization, technical note 81. 53p.

Toreti, A., Kuglitsch, F., Xoplaki, E., Della-Marta, P., Aguilar, E., Prohom, M., and Luterbacher, J., 2011: A note on the use of the standard normal homogeneity test to detect inhomogeneities in climatic time series, Int. J. Climatol., 31, 630-632, doi: 10.1002/joc.2088.

WMO, 1975: Drought and Agriculture, WMO Technical Note 138, WMO, Geneva, Switzerland.

WMO, 1989: Calculation of Monthly and Annual 30-year Standard Normals, WCDP, No. 10, WMO-TD/No. 341, Geneva. 